\title{
Thermal-based modeling of coupled carbon, water, and energy fluxes using nominal light use efficiencies constrained by leaf chlorophyll observations
}

\author{
M. A. Schull ${ }^{1}$, M. C. Anderson ${ }^{1}$, R. Houborg ${ }^{2}$, A. Gitelson ${ }^{3,4}$, and W. P. Kustas ${ }^{1}$ \\ ${ }^{1}$ USDA-ARS Hydrology and Remote Sensing Laboratory, Beltsville, MD, USA \\ ${ }^{2}$ King Abdullah University of Science and Technology, Water Desalination and Reuse Center, Thuwal, Saudi Arabia \\ ${ }^{3}$ Center for Advanced Land Management Information Technology (CALMIT), School of Natural Resources, \\ University of Nebraska-Lincoln, Lincoln, NE, USA \\ ${ }^{4}$ Israel Institute of Technology, Haifa, Israel
}

Correspondence to: M. A. Schull (mitchell.schull@ars.usda.gov)

Received: 11 August 2014 - Published in Biogeosciences Discuss.: 2 October 2014

Revised: 22 January 2015 - Accepted: 24 January 2015 - Published: 11 March 2015

\begin{abstract}
Recent studies have shown that estimates of leaf chlorophyll content (Chl), defined as the combined mass of chlorophyll $a$ and chlorophyll $b$ per unit leaf area, can be useful for constraining estimates of canopy light use efficiency (LUE). Canopy LUE describes the amount of carbon assimilated by a vegetative canopy for a given amount of absorbed photosynthetically active radiation (APAR) and is a key parameter for modeling land-surface carbon fluxes. A carbonenabled version of the remote-sensing-based two-source energy balance (TSEB) model simulates coupled canopy transpiration and carbon assimilation using an analytical submodel of canopy resistance constrained by inputs of nominal LUE $\left(\beta_{n}\right)$, which is modulated within the model in response to varying conditions in light, humidity, ambient $\mathrm{CO}_{2}$ concentration, and temperature. Soil moisture constraints on water and carbon exchange are conveyed to the TSEB-LUE indirectly through thermal infrared measurements of landsurface temperature. We investigate the capability of using Chl estimates for capturing seasonal trends in the canopy $\beta_{n}$ from in situ measurements of $\mathrm{Chl}$ acquired in irrigated and rain-fed fields of soybean and maize near Mead, Nebraska. The results show that field-measured $\mathrm{Chl}$ is nonlinearly related to $\beta_{n}$, with variability primarily related to phenological changes during early growth and senescence. Utilizing seasonally varying $\beta_{n}$ inputs based on an empirical relationship with in situ measured $\mathrm{Chl}$ resulted in improvements in carbon flux estimates from the TSEB model, while adjusting the par-
\end{abstract}

titioning of total water loss between plant transpiration and soil evaporation. The observed $\mathrm{Chl}-\beta_{n}$ relationship provides a functional mechanism for integrating remotely sensed $\mathrm{Chl}$ into the TSEB model, with the potential for improved mapping of coupled carbon, water, and energy fluxes across vegetated landscapes.

\section{Introduction}

The terrestrial biosphere continues to be impacted by climate change and increasing atmospheric carbon dioxide concentrations. Understanding the implications of these changes requires a thorough investigation of the patterns of terrestrial vegetation productivity and its feedback to global biogeochemical cycles of nitrogen and carbon. Vegetation productivity is defined as the production of organic matter by plants through photosynthesis. The total amount of organic matter produced via photosynthesis is known as gross photosynthesis. The total amount of $\mathrm{CO}_{2}$ "fixed" by plants through photosynthesis over a spatial area for a unit time is termed gross primary productivity (GPP) (Gough, 2012).

Numerous micrometeorological studies have focused on measuring the net carbon flux between the atmosphere and land surface, also known as the net ecosystem carbon dioxide exchange (NEE). Field campaigns have been conducted around the world and in many different ecosys- 
tems, often employing the eddy covariance technique to provide information on seasonal and interannual variations in NEE (Baldocchi, 2003). Many studies estimate GPP from eddy covariance observations of NEE and estimates of daytime ecosystem (soil + plant) respiration (Re) as GPP $=\mathrm{NEE}+\mathrm{Re}$ (Suyker and Verma, 2010, 2012). Here, carbon uptake by plants is defined as positive, while respiration, or carbon release, is negative.

Vegetation productivity is largely modulated by the amount of incoming radiation that is intercepted by plants. Many GPP and NEE modeling techniques are based on Monteith's hypothesis that the increase in canopy biomass is linearly related to the amount of light intercepted or absorbed by healthy, unstressed plants (Monteith, 1977). The slope of this relationship is known as the light use efficiency (LUE) or the conversion efficiency of light into biomass through photosynthesis. Many LUE-based models have used fixed values of LUE derived from studies reported in the literature, assigned based on vegetation class (Anderson et al., 2000; Gower et al., 1999). This practice is based on findings that maximum LUE tends to be relatively conservative within broad categories of plant functional type (Field, 1991; Goetz and Prince, 1999; Monteith, 1977).

Recent studies, however, have recognized that a more detailed spatiotemporal representation of LUE is needed to accurately determine the seasonal trends and magnitudes of carbon assimilation rates (Alton et al., 2007; DeLucia et al., 2007; Houborg et al., 2009; Kosugi et al., 2003; Wilson et al., 2001; Xu and Baldocchi, 2003). LUE can vary considerably within vegetation types, at different phenological stages and under varying environmental conditions that induce plant stress (Gower et al., 1999; Houborg et al., 2011, 2013; Medlyn, 1998; Prince, 1991; Ruimy et al., 1999; Xu and Baldocchi, 2003). An analysis conducted by Kergoat et al. (2008) also supports the view that LUE varies significantly across and within biomes as well as among plant functional types. These studies highlight the need to account for variations in LUE due to plant phenological stage as well as changing conditions of light, humidity, and limited water and nutrient resources.

The challenge for regional-scale carbon flux mapping using a LUE-based modeling system is to find a parsimonious yet robust means for specifying LUE spatially across the modeling domain for different land-cover types, and seasonally in response to changing phenology and plant stress conditions. Chlorophyll pigments absorb photosynthetically active radiation (PAR) and constitute a vital element in the photosynthetic machinery. Leaf chlorophyll is mechanistically linked to photosynthetic capacity (Houborg et al., 2013) through functional relationships with leaf nitrogen (Evans, 1989; Schlemmer et al., 2013) and RuBisCO (Sage and Pearcy, 1987; Theobald et al., 1998), which act as a catalyst for carbon fixation within the leaf chloroplasts. These strong correlations make leaf chlorophyll an important control on vegetation productivity by serving as a proxy for the nominal efficiency of leaves in using the absorbed light for photosynthesis. The effective LUE will fluctuate in response to short-term changes in environmental conditions (e.g., temperature, humidity, wind speed), whereas the impact of variations in leaf chlorophyll will be more gradual as vegetation stresses are not immediately manifested in observations of leaf chlorophyll content (Houborg et al., 2011).

Recent studies have shown that the variation in midday GPP can be accurately estimated via measurements of canopy-scale chlorophyll (Gitelson et al., 2006, 2012; Suyker and Verma, 2010, 2012). Changes in canopy chlorophyll are recognized to be sensitive to vegetation stress, crop phenology, and photosynthetic functioning of the vegetation, (Gitelson et al., 2005; Ustin et al., 1999; Zarco-Tejada et al., 2002) and therefore can be related to GPP. Leaf and canopy chlorophyll have also been shown to be useful quantities for constraining the nominal LUE $\left(\beta_{n}\right)$ over the course of the growing season (Gitelson et al., 2006, 2012; Houborg et al., 2011, 2013; Monteith, 1972, 1977; Peng et al., 2011; Peng and Gitelson, 2012). Chlorophyll is a vital pigment in the photosynthetic apparatus, and advances in the retrieval of leaf and canopy chlorophyll from remote sensing data (Houborg et al., 2015) make it extremely amenable for the ultimate goal of mapping fluxes over larger areas.

Houborg et al. (2011) demonstrated the utility of using remotely sensed maps of leaf chlorophyll (Chl), defined as the combined mass of chlorophyll $a$ and chlorophyll $b$ per unit leaf area, generated with the REGularized canopy reFLECtance (REGFLEC) inversion system (Houborg and Anderson, 2009; Houborg et al., 2015) for constraining nominal LUE inputs. REGFLEC-derived maps of $\beta_{n}$ generated over a rain-fed maize production system at the Beltsville Agricultural Research Center (BARC), MD, were used as input to a version of the thermal infrared (TIR) remotesensing-based two-source energy balance model (Anderson et al., 2008; Houborg et al., 2011), which employs an analytical LUE-based model of canopy resistance to compute coupled canopy transpiration and carbon assimilation fluxes (Anderson et al., 2000). Soil moisture constraints on canopy resistance are effectively conveyed to the TSEB-LUE by thermal infrared measurements of land-surface temperature (LST), incorporated via principles of energy balance. Input values of $\beta_{n}$ are modified internally within the model in response to diurnally varying conditions in light, humidity, ambient $\mathrm{CO}_{2}$ concentration and temperature, and inferred soil water status. Houborg et al. (2011) found that REGFLECderived Chl was exponentially related to nominal LUE for drought conditions in 2007. The results improved when a 3day lag between $\mathrm{Chl}$ and $\beta_{n}$ was imposed, suggesting that environmental stresses were not immediately manifested in the measured Chl. Use of a seasonally varying $\beta_{n}$, retrieved as a function of $\mathrm{Chl}$, improved estimates of canopy carbon assimilation as well as latent and sensible heat fluxes in comparison to runs using conventional fixed values of $\beta_{n}$ derived from the literature. 
Here we extend the investigation of functional relationships between $\mathrm{Chl}$ and $\beta_{n}$ using an extensive data set of in situ measurement of $\mathrm{Chl}$ collected fields of both irrigated and rain-fed maize and soybean in Mead, NE. An empirically derived functional form of Chl versus nominal $\beta_{n}$ is used to drive the TSEB-LUE model at these sites using in situ measurements of LST, Chl, and micrometeorological variables, and model performance is evaluated using flux data from eddy covariance towers situated within the fields. A follow-on study will incorporate the TSEB-LUE into a multiscale regional energy balance modeling system (Anderson et al., 2007) using $\beta_{n}$ fields retrieved from remotely sensed estimates of Chl, enabling routine mapping of coupled carbon, water, and energy fluxes at field to regional scales while taking into account critical spatiotemporal variations in photosynthetic capacities.

\section{Model description}

\section{$2.1 \quad$ TSEB}

The two-source (soil + canopy) energy balance (TSEB) model (Norman et al., 1995) is a thermal-based diagnostic flux model that couples micrometeorological conditions inside and above the canopy to energy fluxes from the soil, plants and atmosphere (Fig. 1). The TSEB land-surface model and refinements (Kustas and Norman, 1999, 2000) have been implemented within the Atmosphere-Land Exchange Inverse (ALEXI) regional modeling system, and the associated DisALEXI flux disaggregation approach (Anderson et al., 2007). The ALEXI-DisALEXI modeling paradigm facilitates flux mapping at continental to field scales through a combination of TIR imagery from geostationary and polar orbiting sensors (Anderson et al., 2011). The research in this paper, focusing on a local application of the TSEB approach using tower-based inputs, will be used to further refine regional remote-sensing-based flux mapping applications using ALEXI-DisALEXI.

The modeling system described here uses the series version of the TSEB (Kustas and Norman, 2000), which partitions available energy at the surface into sensible and latent heat fluxes. The fluxes are computed separately for soil (subscript "s") and canopy (subscript "c") components of the TIR measurement footprint:

$\left(\mathrm{RN}_{\mathrm{c}}+\mathrm{RN}_{\mathrm{s}}\right)-G=\left(H_{\mathrm{c}}+H_{\mathrm{s}}\right)+\left(\mathrm{LE}_{\mathrm{c}}+\mathrm{LE}_{\mathrm{s}}\right)$.

The canopy and soil components of the net radiation $\left(\mathrm{RN}_{\mathrm{c}}\right.$, $\mathrm{RN}_{\mathrm{s}}$ ) are modeled using equations found in Kustas and Norman (1999), while $G$ is computed as a time-dependent fraction of $\mathrm{RN}_{\mathrm{S}}$ (Santanello and Friedl, 2003). The model partitions remotely sensed LST ( $\left.T_{\text {rad }}\right)$, observed at a view angle $\theta$, into canopy and soil temperature components as

$T_{\mathrm{rad}}(\theta)=\left[f_{\theta} T_{\mathrm{c}}^{4}+\left(1-f_{\theta}\right) T_{\mathrm{s}}^{4}\right]^{1 / 4}$.
Here $f_{\theta}$ is the fraction of vegetation cover as apparent from the TIR sensor view angle:

$f_{\theta}=1-\exp \left(\frac{-0.5 \Omega_{\theta} \mathrm{LAI}}{\cos \theta}\right)$,

where LAI is the leaf area index $\left(\mathrm{m}^{2} \mathrm{~m}^{-2}\right)$ and $\Omega_{\theta}$ is an angle-dependent vegetation-clumping factor. Sensible heat flux from the soil $\left(H_{\mathrm{s}}\right)$ and canopy $\left(H_{\mathrm{c}}\right)$ and combined system $(H)$ are then computed from the partitioned temperatures of canopy $\left(T_{\mathrm{c}}\right)$ and soil $\left(T_{\mathrm{s}}\right)$ using a temperature gradient series resistance network connecting the soil, canopy, and atmosphere:

$$
\begin{aligned}
H_{\mathrm{c}} & =\rho c_{\mathrm{p}} \frac{T_{\mathrm{c}}-T_{\mathrm{AC}}}{R_{X}}, \\
H_{\mathrm{s}} & =\rho c_{\mathrm{p}} \frac{T_{\mathrm{s}}-T_{\mathrm{AC}}}{R_{\mathrm{s}}}, \\
H & =\rho c_{\mathrm{p}} \frac{T_{\mathrm{AC}}-T_{\mathrm{A}}}{R_{\mathrm{A}}},
\end{aligned}
$$

where $R_{X}$ is the total two-sided leaf boundary resistance, $R_{\mathrm{S}}$ is the soil boundary resistance, and $R_{\mathrm{A}}$ is the aerodynamic resistance. The upper boundary condition in air temperature, $T_{\mathrm{A}}$, is measured or estimated at a reference height above the canopy, while $T_{\mathrm{AC}}$ is a model-diagnosed in-canopy temperature. In the original form of the TSEB (referred to here as TSEB-PT), $\mathrm{LE}_{\mathrm{c}}$ is computed using a modified PriestleyTaylor (PT) approach (Norman et al., 1995) applied to the divergence of net radiation within the canopy. Soil evaporation, $\mathrm{LE}_{\mathrm{s}}$, is calculated as a residual in the energy balance equations. Negative $L_{\mathrm{S}}$ values obtained at midday, indicating condensation onto the soil, are considered non-physical and likely result from an overestimation of $\mathrm{LE}_{\mathrm{c}}$ by the PT approximation. This may occur under conditions of vegetation stress, where the rate of transpiration is reduced from the potential PT estimate due to stomatal closure. In such conditions the PT coefficient is iteratively reduced until $\mathrm{LE}_{\mathrm{s}}$ approaches zero (Kustas et al., 2004).

\subsection{Analytical canopy resistance submodel (TSEB-LUE)}

Anderson et al. (2008) replaced the PT approximation for $\mathrm{LE}_{\mathrm{c}}$ in TSEB-PT with an estimate of canopy transpiration generated using an analytical LUE-based model of canopy resistance (Anderson et al., 2000), enabling simulation of carbon fluxes in addition to energy and water fluxes to the atmosphere. In comparison with TSEB-PT, TSEB-LUE requires additional atmospheric inputs of ambient vapor pressure and $\mathrm{CO}_{2}$ concentration, which serve as the upper boundary for flux-gradient calculations of $\mathrm{LE}_{\mathrm{c}}$ and $A_{\mathrm{c}}$. It also requires specification of $\beta_{n}$, the LUE expected under nominal unstressed conditions.

The system of equations and computational strategy used in TSEB-LUE are described in full in Anderson et al. (2008). 


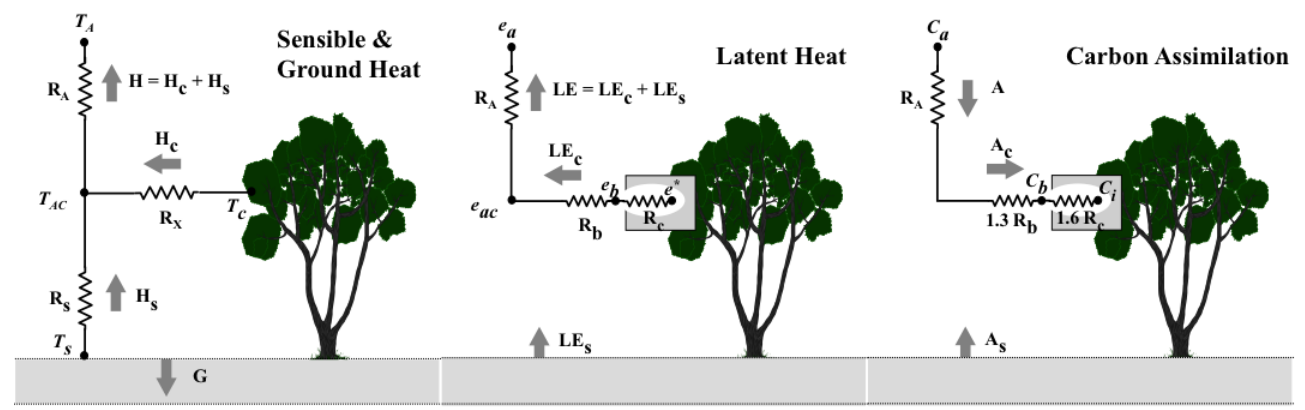

Figure 1. Schematic illustrating the LUE-based canopy resistance method, diagramming its role within TSEB framework for computing coupled carbon, water, and energy fluxes.

In brief, in TSEB-LUE $\mathrm{LE}_{\mathrm{c}}$ and $A_{\mathrm{c}}$ are both defined using gradient-resistance equations as shown in Fig. 1, coupled through simulated values of bulk canopy resistance $\left(R_{\mathrm{c}}\right)$. Energy balance constraints on $\mathrm{LE}_{\mathrm{c}}$ (informed by the $T_{\mathrm{c}}$ component of the remotely sensed LST input) and LUE constraints on $A_{\mathrm{c}}$ (informed by the $\beta_{n}$ input, typically assigned by land-cover class) are used in combination to solve for $R_{\mathrm{c}}$, as well as water vapor and carbon concentrations inside the leaf and canopy. The bulk leaf boundary layer resistance $\left(R_{\mathrm{b}}\right)$ and aerodynamic resistance $\left(R_{\mathrm{A}}\right)$ in Fig. 1 are dependent on wind speed and stability conditions, as described in Anderson et al. (2000). Here $R_{\mathrm{b}}$, the canopy integrated two-sided leaf boundary layer resistance, is related to $R_{X}$, the total twosided leaf boundary resistance as $R_{\mathrm{b}}=\left(f_{\mathrm{s}} /\left[f_{\mathrm{g}} \cdot f_{\mathrm{dry}}\right]\right) R_{X}$, where $f_{\mathrm{s}}$ is distribution of stomata over the top and bottom of the leaf, $f_{\mathrm{g}}$ is the fraction of green vegetation, and $f_{\text {dry }}$ excludes the fraction of stomata that is blocked by leaf surface water. For a more detailed illustration of the coupled nature of the $\mathrm{LE}_{\mathrm{c}}$ and $A_{\mathrm{c}}$, the reader is directed to Eqs. (A13) and (A14) in the Appendix of Anderson et al. (2008). Here we can see that the fluxes of $\mathrm{LE}_{\mathrm{c}}$ and $A_{\mathrm{c}}$ are governed by $R_{\mathrm{c}}$.

The LUE constraints on $A_{\mathrm{c}}$ are imposed as

$A_{\mathrm{c}}=\beta(\gamma) \cdot \mathrm{APAR}$,

where $\beta$ is the effective LUE and $\gamma$ is the ratio of intercellular $\left(C_{\mathrm{i}}\right)$ to ambient $\left(C_{\mathrm{a}}\right) \mathrm{CO}_{2}$ concentrations as diagnosed by the model and APAR is the absorbed photosynthetically active radiation. Under unstressed conditions we assume that the canopy will operate near $\beta_{n}$ and a nominal value of $C_{\mathrm{i}} / C_{\mathrm{a}}\left(\gamma_{n}\right)$. While curvilinear at the scale of individual leaves, the relationship between $A_{\mathrm{c}}$ and $C_{\mathrm{i}}$ has been shown to be more linearized at the canopy scale (Norman and Arkebauer, 1991). Therefore the deviation of effective LUE from the nominal value is estimated through the linear relationship

$\beta(\gamma)=\frac{\beta_{n}}{\gamma_{n}-\gamma_{0}}\left(\gamma-\gamma_{0}\right)$,

where $\gamma_{0}$ is the value of $\gamma$ when $\beta$ is zero.
Anderson et al. (2008) determined that deviations of effective LUE from the nominal value $\Delta \beta=\beta_{n}-\beta$, generated by the TSEB-LUE, reflect both variability in ambient meteorological conditions and surface moisture conditions implied by the thermal signal. For example, riparian areas where soil moisture was non-limiting showed minimal $\Delta \beta$, while in areas with dense vegetation but relatively high $T_{\mathrm{c}}$ (in comparison with values expected for well-watered vegetation), $\beta$ was depressed more significantly from the nominally assigned value. This indicates that the TIR inputs were conveying useful information regarding moisture limitations on both canopy resistance and effective LUE - without the need for precipitation input data and a detailed soil water balance characterization.

The study by Anderson et al. (2008) assumed that the nominal LUE is constant in time for a given plant functional type. However, numerous studies cited above, including seasonal tests with TSEB-LUE (Houborg et al., 2011), have demonstrated that the nominal value of LUE can vary seasonally based on stand phenology and the canopy's changing capacity to fix carbon. Here we investigate the ability of measurements of leaf chlorophyll content in maize and soybean to accurately reflect seasonal changes in the $\beta_{n}$ required by TSEBLUE throughout several growing seasons and under different water management strategies.

\section{Materials and methods}

\subsection{Study site}

This study uses data collected between 2002 and 2005 at the University of Nebraska-Lincoln Agriculture and Development Center as part of the ongoing Carbon Sequestration Program. The research facility is located about $58 \mathrm{~km}$ northeast of Lincoln, NE, USA, and consists of three $\sim 65$ ha fields of maize (Zea mays, L) and soybean (Glycine max [L.] Merr.) (Fig. 2). Table 1 summarizes crop and water management by field for 2002-2005. Field 1 was planted with continuous maize throughout the study period, while fields 2 and 3 supported a maize/soybean rotation cropping system. 


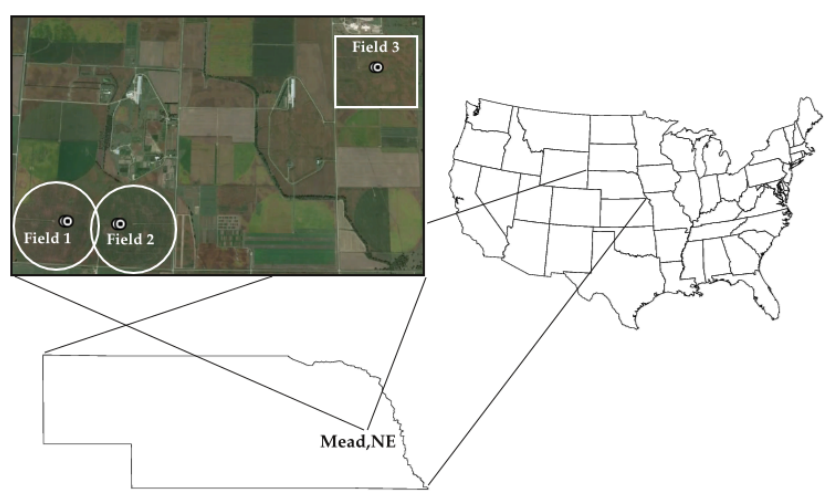

Figure 2. Location of the irrigated (lower left) and rain-fed (upper right) study fields. The white dots represent the locations of the micrometeorological towers.

Fields 1 and 2 are equipped with a center pivot irrigation system, while field 3 relies entirely on rainfall. All three fields were under no-till management from 2001 through the extent of the study period examined here. Additional details regarding long-term crop management and measurement activities at these field sites are provided in Suyker and Verma (2010).

\subsection{Micrometeorological observations}

An eddy covariance (EC) system has been deployed in each field, collecting continuous measurements of latent heat (LE), sensible heat $(H), \mathrm{CO}_{2}$ (NEE), and momentum fluxes. These fluxes are routinely reported and available to the public as part of the AmeriFlux program. Details regarding the flux and supporting micrometeorological instrumentation at Mead are described in Suyker and Verma (2010). In order to ensure the flux footprint/source area originated essentially from the field encompassing the flux tower, the eddy covariance sensors were mounted at $3 \mathrm{~m}$ above the ground level for plant canopies that were shorter than $1 \mathrm{~m}$ and were moved to $6.2 \mathrm{~m}$ as the plant canopies grew for the remainder of each growing season.

Ancillary micrometeorological measurements were collected routinely on a separate tower near each flux tower. The additional measurements include incident direct and diffuse photosynthetically active radiation, with absorbed PAR (APAR) quantified using point and line quantum sensors above and below the canopy. Air temperature and humidity were measured at 3 and $6 \mathrm{~m}$ above ground level, and radiation at $5.5 \mathrm{~m}$. Multiple in- and between-row measurements of soil heat flux at $0.06 \mathrm{~m}$ depth were combined to approximate an average flux. Soil heat flux $(G)$ values used here were corrected for heat storage above the plates.

EC fluxes computed for half hour intervals were assessed for closure of the energy budget by comparing LE $+H$ and $\mathrm{RN}+G$ during the study period. The regression slopes over the study period ranged from 0.9 to 1 , indicating generally reasonable closure. For comparison with model results, en- ergy closure was enforced by modifying the observed sensible and latent heat fluxes such that the observed Bowen ratio was maintained (Twine et al., 2000).

\subsection{Biophysical measurements}

In order to facilitate research studies, biophysical data were collected continuously over the study period at six small plots $(20 \mathrm{~m} \times 20 \mathrm{~m})$ in each field. These plots, known as intensive measurement zones (IMZs), were established such that they represent all major occurrences of soil and crop production zones within each field (Gitelson et al., 2003b; Viña, 2004). The collection of biophysical data within the IMZ areas is described in detail by Viña (2004) and only briefly reviewed here.

Within each IMZ, average leaf area per plant was estimated for both live and dead leaves using destructive samples collected every 10-14 days and measured using a LI3100 area meter (LI-COR Inc., Lincoln, NE, USA). The total leaf area (LAI) and the green leaf area (LAIg) were calculated as the leaf area per plant multiplied by the plant density (plants $\mathrm{m}^{-2}$ ) at each IMZ. The LAI samples collected at the six IMZs were area-weighted to obtain field-wide representative values (Gitelson et al., 2006).

The canopy-clumping factor, $\Omega$, used in Eq. (3), was empirically estimated for each site by optimizing the radiation scheme in TSEB-LUE such that modeled midday APAR values matched observed values. Optimized $\Omega$ on non-clear days (fraction of direct radiation $\left(f_{\text {dir }}\right)<80 \%$ ) were removed and a linear interpolation between clear day values was applied. The allowed range in retrieved clumping factor ranged between 0.6 and 1.0.

In addition to LAI, reflectance measurements of the upper canopy leaves were taken every 2 weeks using an Ocean Optics USB2000 radiometer (400-900 nm) equipped with a leaf clip (Gitelson et al., 2005; Viña et al., 2011). The Chl content was estimated from the reflectance data using a non-destructive methodology (Ciganda et al., 2009; Gitelson et al., 2003b). The method utilizes reflectance in the red edge $(700-720 \mathrm{~nm})$ and NIR $(760-800 \mathrm{~nm})$ regions to approximate total $\mathrm{Chl}$, where $\mathrm{Chl}=a \cdot\left[\left(R_{\mathrm{NIR}} / R_{\text {red edge }}\right)-1\right]$ $\left(\mu \mathrm{g} \mathrm{cm}^{-2}\right)$. The model coefficient $a$ was calibrated using total $\mathrm{Chl}$ extracted in the lab. The linear model allowed for estimates of $\mathrm{Chl}$ in the range of $1-90 \mu \mathrm{g} \mathrm{cm}^{-2}$ with a rootmean-square error (RMSE) below $6 \mu \mathrm{g} \mathrm{cm}^{-2}$. In order to estimate average leaf chlorophyll content within the plant stand, leaf level measurements of chlorophyll were multiplied by the fraction of green leaves $\left(f_{\mathrm{g}}\right)$

$\mathrm{Chl}=\mathrm{Chl}_{\text {live }} \cdot f_{\mathrm{g}}$,

where $f_{\mathrm{g}}$ was computed as the ratio of green (LAIg) to total LAI, LAIg / LAI. 
Table 1. Cropping and water management history at Mead study field sites.

\begin{tabular}{lllll}
\hline & \multicolumn{4}{c}{ Year } \\
\cline { 2 - 5 } & 2002 & 2003 & 2004 & 2005 \\
\hline Field 1 & Irrigated corn & Irrigated corn & Irrigated corn & Irrigated corn \\
Field 2 & Irrigated soybean & Irrigated corn & Irrigated soybean & Irrigated corn \\
Field 3 & Rain-fed soybean & Rain-fed corn & NA & Rain-fed corn \\
\hline
\end{tabular}

\subsection{Soil respiration and canopy assimilation}

TSEB-LUE estimates net carbon assimilation by the canopy $\left(A_{\mathrm{c}}\right)$. To evaluate model output, the EC measurements of NEE ( $A=A_{\mathrm{c}}-A_{\mathrm{s}}$ in Fig. 1$)$ must be corrected using estimates of the soil respiration flux, $A_{\mathrm{s}}$. Soil respiration was measured at approximately 3 -week intervals at each field site using a portable gas exchange system. Along with each soil respiration measurement, soil temperatures at $10 \mathrm{~cm}$ were recorded and gravimetric soil water content was determined for a $0-10 \mathrm{~cm}$ soil sample and converted to volumetric water contents $\left(\theta_{10}\right)$ using measured bulk densities.

In order to interpolate between sampling dates, the measured soil respiration fluxes were fit to an empirical equation (Norman et al., 1992) describing $A_{\mathrm{s}}$ as a function of soil temperature $\left(T_{\mathrm{S}}\right)$, soil moisture, and LAI:

$A_{\mathrm{s}}=(a+b \mathrm{LAI}) \theta_{10} \exp \left[c\left(T_{\mathrm{s}, 10-25.0}\right)\right]$,

where $\theta_{10}$ is the soil moisture content in the $0-10 \mathrm{~cm}$ depth; $T_{\mathrm{s}, 10}$ is the temperature of the soil at a depth of $10 \mathrm{~cm}$; and the site-specific regression coefficients $a, b$, and $c$ were derived empirically every year for each field. The hourly canopy carbon assimilation $\left(A_{\mathrm{c}}\right)$ was then obtained by adding estimates of hourly soil respiration $\left(A_{\mathrm{s}}\right)$, derived from hourly in-field observations of $\theta_{10}$ and $T_{\mathrm{s}, 10}$ along with daily interpolated LAI, to net ecosystem exchange $(A)$ (sign convention used here is such that $A_{\mathrm{c}}$ and $A_{\mathrm{s}}$ are positive away from the surface).

\subsection{Nominal LUE optimization}

The seasonal variation in model input values of $\beta_{n}$ was determined at 5-day intervals for each field and study year by minimizing differences between measured and modeled canopy $\mathrm{CO}_{2}$ fluxes $\left(A_{\mathrm{c}}\right)$. The TSEB-LUE model was run for all three fields using tower measurements of incident solar radiation, incoming longwave radiation, air temperature, wind speed, atmospheric pressure, and vapor pressure, as well as outgoing longwave radiation. The measured outgoing longwave radiation was inverted using the Stefan-Boltzmann law to estimate half-hourly LST $\left(T_{\mathrm{RAD}}\right)$. Previous studies (Goetz et al., 1995; Hatfield et al., 1984) have indicated that this provides a more representative measurement of the composite (soil + vegetation) surface temperature than do measurements from infrared thermometers, which have a rela- tively narrow field of view. These runs used leaf and canopy parameters for maize and soybean tabulated in Houborg et al. (2009), and field-average estimates of LAI (Sect. 3.3) linearly interpolated to daily values over the study period.

Following Houborg et al. (2011), the optimization process varied $\beta_{n}$ over a prescribed range, selecting daily values that minimized bias between modeled and measured Ac fluxes during daytime hours (constrained to solar zenith angles (SZA) less than $50^{\circ}$ ). Optimized values of $\beta_{n}$ were then averaged over 5-day periods. Only clear days were considered, defined such that the fraction of direct radiation was greater than $50 \%$. LUE is known to increase under more diffuse lighting conditions because light is more uniformly distributed over the canopy (Norman and Arkebauer, 1991). By constraining to clear days, the resulting optimized $\beta_{n}$ are relevant to future remote sensing applications, which require clear-sky conditions for direct retrieval of TIR-based LST and a gap-filling algorithm for estimating fluxes during cloudy periods. In addition, we considered fluxes only over medium to dense vegetation (LAI $>2$ ) where Ac dominates the observed system $\mathrm{CO}_{2}$ flux and $\beta_{n}$ optimization is well constrained. The end product was a time series of 5-dayaveraged $\beta_{n}$ determined over the growing season for each year and site, optimized for use within the TSEB-LUE modeling framework.

\section{Results and discussion}

\subsection{Relationship between $\mathrm{Chl}$ and $\boldsymbol{\beta}_{n}$}

Figure 3 shows examples of the time evolution of optimized nominal LUE and measurements of Chl over the growing season obtained for representative irrigated soybean (a) and maize (b) fields. There is a general correspondence between time trends in $\beta_{n}$ and Chl, but with some deviation particularly in the beginning of the season, when LAI is low. At these times, the canopy assimilation is small and optimization of $\beta_{n}$ using measured Ac is not as reliable. Therefore, in deriving empirical functional relationships between $\beta_{n}$ and Chl we only consider observations collected over medium to dense vegetation (LAI > 2) where canopy carbon assimilation is significant. This does not imply, however, that the functional relationships cannot be used over sparse vegeta- 

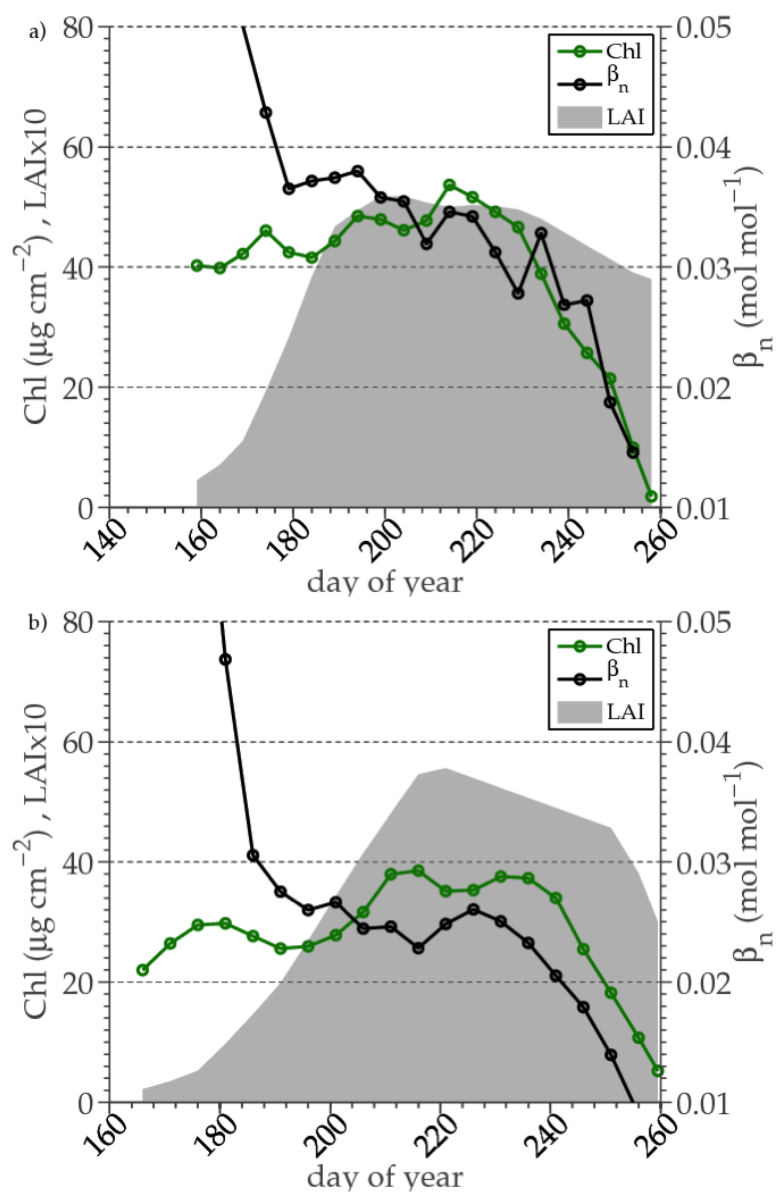

Figure 3. Seasonal trends of $\beta_{n}$, leaf Chl, and LAI for (a) an irrigated maize field (field 1, 2005) and (b) an irrigated soybean field (field 2, 2002).

tion. The results discussed in Sects. 4.2 and 4.3 and in Tables 3 and 4 show results from sparse to dense vegetation.

Scatterplot comparisons of $\beta_{n}$ and Chl for all sites and years are shown in Fig. 4, discriminating maize from soybean and irrigated from rainfed fields. Nominal LUE is shown to be nonlinearly sensitive to $\mathrm{Chl}$, and the reasonable goodness of fit $\left(r^{2}=0.52\right)$ provides support for the use of $\mathrm{Chl}$ as a remote sensing observable for retrieving $\beta_{n}$ inputs to TSEB-LUE. While separate functional relationships for soybean and maize were explored (not shown), the benefits of employing these species-specific relationships did not outweigh the advantage of having a single functional fit. A more elaborate data set on soybean will be needed for further investigations into functional differences in the Chl- $\beta_{n}$ response between soybean and maize. Figure 4 indicates that a single function can be used to describe the relationship for both crops, despite the differences in photosynthetic pathway between soybean (C3) and maize (C4) crops. While semimechanistic relationships between leaf chlorophyll content and leaf photosynthetic capacity demonstrate the importance

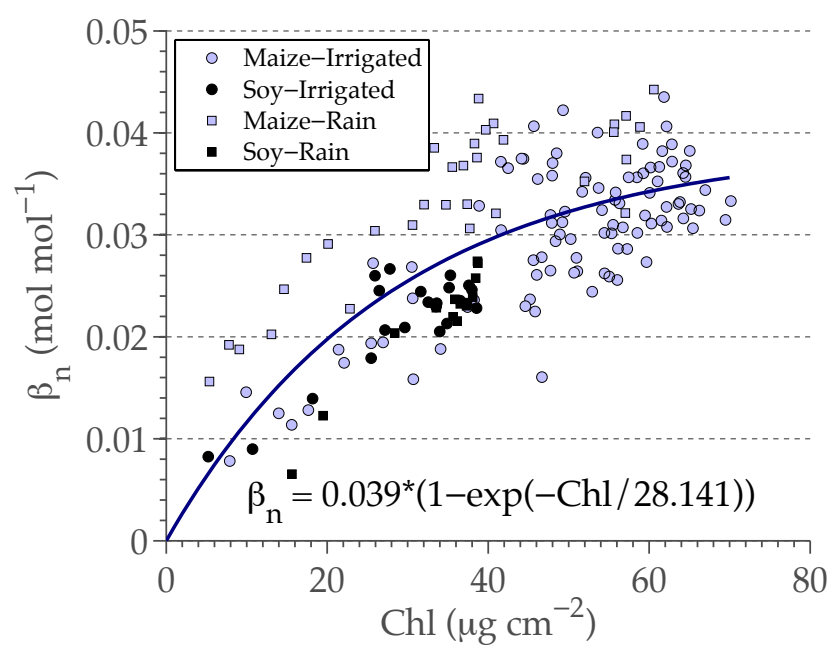

Figure 4. Functional relationship derived between $\mathrm{Chl}$ and $\beta_{n}$ for irrigated and rain-fed fields of maize and soybean.

of distinguishing between species utilizing differing photosynthetic pathways (C3 versus C4) (Houborg et al., 2013), relationships at the canopy scale are governed by different mechanism sometimes yielding more universal relationships (Gitelson et al., 2006). For soybean, assimilation rate begins to saturate at approximately $30\left(\mu \mathrm{g} \mathrm{cm}^{-2}\right) \mathrm{Chl}$, corresponding to a $\beta_{n}$ of 0.025 (Fig. 4). $\mathrm{C}_{4}$ crops can assimilate more carbon per unit APAR by maintaining the concentration of $\mathrm{CO}_{2}$ at a high level in the leaf so that photorespiration is minimized, and saturation occurs at a higher $\mathrm{Chl}\left(\sim 60 \mu \mathrm{g} \mathrm{cm}^{-2}\right)$ and $\beta_{n}$ $(\sim 0.035)$ value. These are close to the conventional values of $\beta_{n}$ found in the literature such as those used in the fixed $\beta_{n}$ studies of Anderson et al. $(2008,2000)$ and Houborg et al. (2009).

The functional fit for $\beta_{n}(\mathrm{Chl})$ plotted in Fig. 4 takes the form of $\beta_{n}=a(1-\exp (b \cdot \mathrm{Chl}))$ and was composed using a customized nonlinear least squares fit. The approach finds the regression coefficients that minimize the error between $x$ (Chl) and $y\left(\beta_{n}\right)$. Here the coefficients $a$ (95\% confidence bounds) and $b$ are $0.039(0.038,0.040)$ and $28.14(26.18$, 30.10 ), respectively, with an $r^{2}$ of 0.52 . A leave-one-out cross-validation reveals that $\beta_{n}$ can be estimated from $\mathrm{Chl}$ with an RMSE of $0.0042 \mathrm{~mol} \mathrm{~mol}^{-1}$ for both maize and soybean.

Though it is evident that there is a considerable amount of deviation from the functional fit, there are some potential explanations for this deviation. The outliers that appear to have higher $\beta_{n}$ values for low $\mathrm{Chl}$ values are predominantly rain-fed maize (Fig. 4). A lower planting density to maximize efficiency could explain these outliers. In fact, the rain-fed field 3 is planted at a lower density for both maize and soybean (Table 2). Lower plant density appears to have little affect on soybean, likely due to the difference in plant structure. In maize a lower planting density allows deeper penetration of light into the canopy and an increase in the in- 
Table 2. Planting density (plants $\mathrm{m}^{-2}$ ). NA: not available.

\begin{tabular}{ccccc}
\hline & \multicolumn{4}{c}{ Year } \\
\cline { 2 - 5 } & 2002 & 2003 & 2004 & 2005 \\
\hline Field 1 & 7.1 & 7.7 & 8.0 & 6.9 \\
Field 2 & 33.3 & 7.8 & 29.6 & 7.6 \\
Field 3 & 30.5 & 5.7 & NA & 5.4 \\
\hline
\end{tabular}

Table 3. Statistical metrics for hourly measured and modeled fluxes using two-thirds of the fields/years for validation. Energy flux units are $\mathrm{W} \mathrm{m}^{-2}$ and carbon flux units are $\mu \mathrm{mol} \mathrm{m}^{-2} \mathrm{~s}^{-1}$.

\begin{tabular}{lccccccc}
\hline Flux & $N$ & $O$ & MBE & RMSD & $r^{2}$ & $E$ & $\%$ error \\
\hline Fixed & & & & & & & \\
RN & 1680 & 347 & 6 & 29 & 0.89 & 0.98 & 5 \\
LE & 1680 & 268 & 0 & 51 & 0.84 & 0.90 & 14 \\
H & 1680 & 43 & -4 & 35 & 0.68 & 0.76 & 62 \\
G & 1680 & 41 & 7 & 23 & 0.68 & 0.73 & 42 \\
Ac & 1680 & 23 & 5 & 9 & 0.83 & 0.68 & 28 \\
\hline$f($ Chl $)$ & & & & & & & \\
RN & 1680 & 347 & 5 & 29 & 0.88 & 0.98 & 5 \\
LE & 1680 & 269 & -5 & 52 & 0.82 & 0.90 & 14 \\
H & 1680 & 45 & 0 & 35 & 0.67 & 0.77 & 59 \\
G & 1680 & 40 & 7 & 22 & 0.70 & 0.75 & 42 \\
Ac & 1680 & 23 & 2 & 5 & 0.91 & 0.90 & 18 \\
\hline
\end{tabular}

Here $N$ is the number of observations, $O$ is the mean observed flux, RMSD is the root-mean-square difference between the modeled $(P)$ and observed $(O)$ values, MBE is the mean bias error $(P-O), r^{2}$ is the coefficient of determination for the linear regression of $P$ on $O, E$ is the coefficient of efficiency, and the percent error is defined as the mean absolute difference between $P$ and $O$ divided by the mean observed flux.

tensity of diffuse light, which can enhance effective LUE by up to $15 \%$ in maize (Norman and Arkebauer, 1991). Another important factor may be the adopted multiplication of in situ measured $\mathrm{Chl}$ with the fraction of green vegetation in order to produce an average (comprising both green and senescent leaf material) $\mathrm{Chl}$ over the canopy (Houborg et al., 2015). This assumes in situ sampling of entirely green leaf material, which may result in underestimation of the actual Chl particularly during advanced stages of leaf senescence or vegetation stress. This is particularly evident in the rain-fed fields of maize as seen in Fig. 4.

\subsection{Evaluation of hourly fluxes from TSEB-LUE}

Seasonal variations in both total latent heat flux and carbon assimilation over representative fields of irrigated maize and soybean are shown in Fig. 5. Each diurnal segment is represented by flux measurements averaged by hour over 5-day intervals. The averaging scheme reduces the random errors associated with flux observations as well as natural variability for each time period (Moncrieff et al., 1996). Statistical metrics comparing observed and modeled fluxes at the hourly time step are tabulated in Table 3, including mean bias error
Table 4. Statistical metrics comparing daily measured and modeled fluxes using two-thirds of the fields/years for validation. Energy flux units are $\mathrm{MJ} \mathrm{m}^{-2} \mathrm{~d}^{-1}$ and carbon flux units are $\mathrm{gCm}^{-2} \mathrm{~d}^{-1}$.

\begin{tabular}{lccccccc}
\hline Flux & $N$ & $O$ & MBE & RMSD & $r^{2}$ & $E$ & \% error \\
\hline Fixed & & & & & & & \\
RN & 140 & 14 & 0.21 & 0.76 & 0.97 & 0.96 & 4 \\
LE & 140 & 11 & 0.18 & 1.44 & 0.89 & 0.89 & 10 \\
H & 140 & 2 & -0.08 & 1.07 & 0.76 & 0.74 & 50 \\
G & 140 & 2 & 0.23 & 0.58 & 0.77 & 0.66 & 25 \\
Ac & 140 & 2 & 0.47 & 0.60 & 0.91 & 0.64 & 26 \\
\hline$f($ Chl $)$ & & & & & & & \\
RN & 140 & 14 & 0.1 & 0.74 & 0.97 & 0.96 & 4 \\
LE & 140 & 11 & -0.16 & 1.41 & 0.88 & 0.88 & 10 \\
H & 140 & 2 & 0.07 & 1.03 & 0.78 & 0.76 & 55 \\
G & 140 & 2 & 0.29 & 0.61 & 0.77 & 0.65 & 27 \\
Ac & 140 & 2 & 0.14 & 0.32 & 0.92 & 0.90 & 13 \\
\hline
\end{tabular}

(MBE), root-mean-square difference (RMSD), coefficient of regression $\left(r^{2}\right)$, coefficient of efficiency $(E)$, and percent error (\% error). The statistics in Table 3 are generated from a randomly selected two-thirds of the data set to test the robustness of the Chl- $\beta_{n}$ functional fit.

The impact of including the seasonally varying nominal LUE (as a function of Chl) in the TSEB-LUE is most evident in model estimates of carbon assimilation (Fig. 5a,b), with lesser impact on total fluxes of latent (Fig. 5c,d) and sensible heat. Differences between simulated carbon fluxes forced using a fixed $\beta_{n}$ (red line) and a $\beta_{n}$ dictated by variations in Chl (blue line) are particularly pronounced for maize (Fig. 5a), especially during senescence. Statistical metrics describing model performance at a hourly time step (Table 3) demonstrate a significant decrease in the RMSD from 9 to $5 \mu \mathrm{mol} \mathrm{m}{ }^{-2} \mathrm{~s}^{-1}$ when adopting seasonally varying $\beta_{n}$ (as a function of Chl) rather than a fixed $\beta_{n}$. The coefficient of determination improves from 0.83 to 0.91 , the coefficient of efficiency increases from 0.68 to 0.90 , and the relative error is reduced to $18 \%$ using a varying $\beta_{n}$ down from $28 \%$ using a fixed $\beta_{n}$ (Table 3 ). Clearly, by adopting fixed literature-based $\beta_{n}$ values designed for healthy vegetation, carbon assimilation may be overestimated during times of vegetation stress and senescence and underestimated during times of optimal plant health.

In this study, the impact on the total latent heat flux was minimal, as evidenced by the RMSD values of 51 and $52 \mathrm{~W} \mathrm{~m}^{-2}$ using seasonally fixed values of $\beta_{n}$ and $\beta_{n}(\mathrm{Chl})$, respectively (Table 3 ). Impacts on sensible heat fluxes were similarly minimal. In contrast, Houborg et al. (2011) noted a significant improvement in latent heat fluxes over maize during severe drought conditions. The data sets used in the current analysis are based on collections over irrigated and to a lesser extent rain-fed fields not significantly affected by drought conditions over the studied period, and more re- 

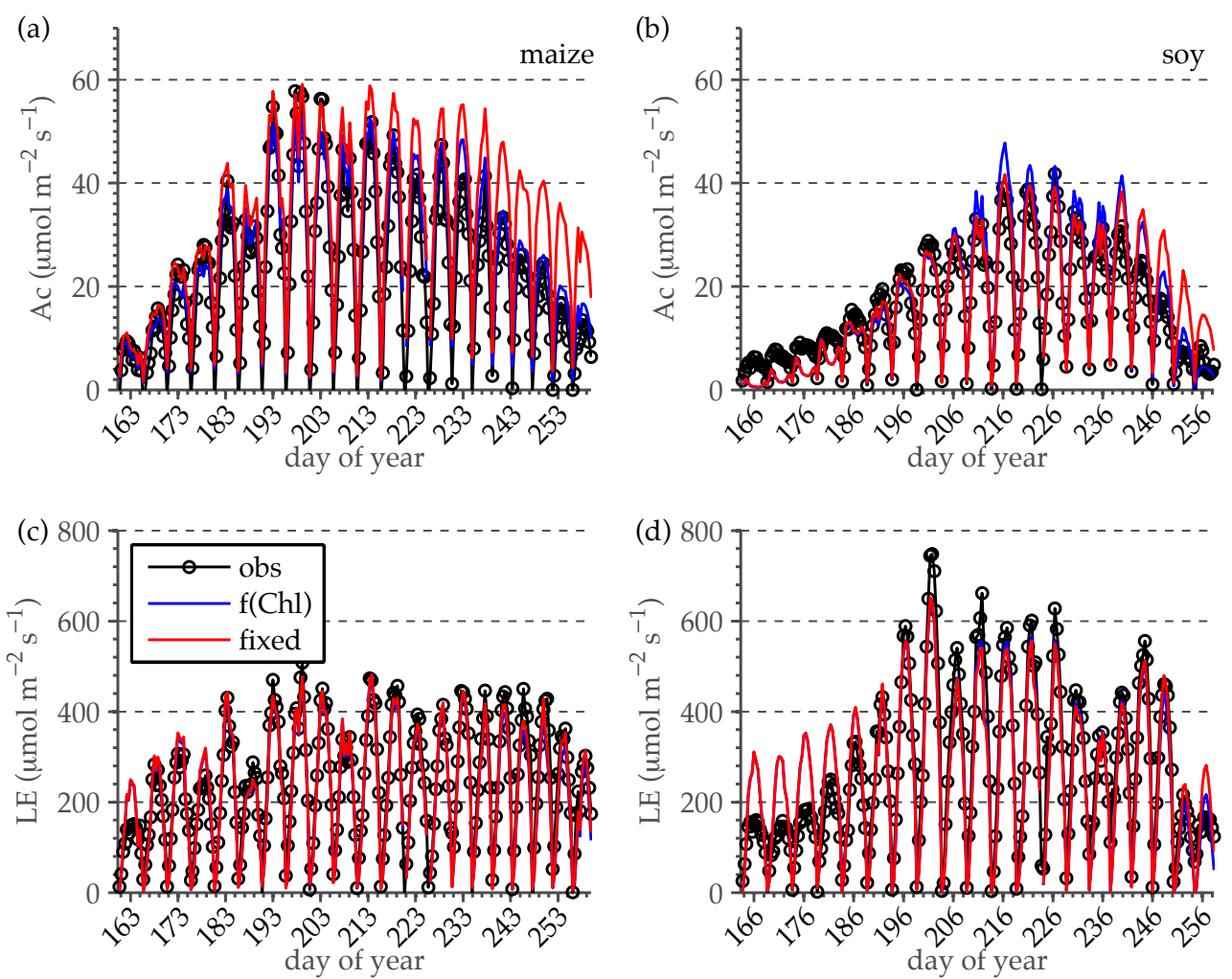

Figure 5. Seasonal variations in hourly canopy fluxes of carbon and latent heat over maize (left panels: field 1, 2004) and soybean (right panels: field 2, 2002). Fluxes modeled using fixed $\beta_{n}$ are shown in red and fluxes modeled using $\beta_{n}$ as a function of Chl are shown in blue. Each diurnal period shown represents fluxes averaged hourly over a 5-day segment.

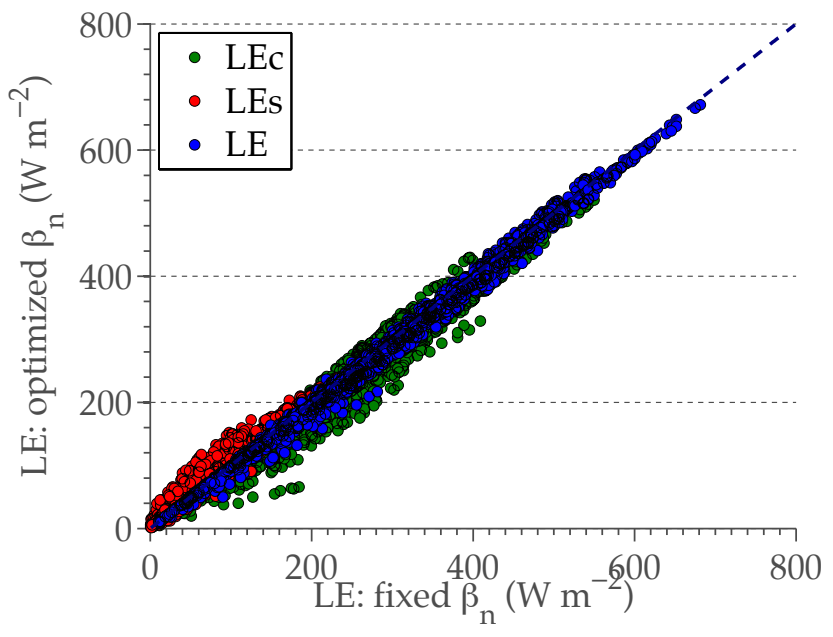

Figure 6. Comparison of hourly TSEB-LUE estimates of latent heat flux over maize and soybean field, generated using a fixed values $\beta_{n}$ and using $\beta_{n}$ as a function of Chl. The green circles are the latent heat fluxes from the canopy and red circles represent latent heat fluxes from the soil. The blue filled circles are the total (soil + canopy) latent heat fluxes.

search is still needed to reveal the impact of drought stress on $\beta_{n}$ and latent heat fluxes.

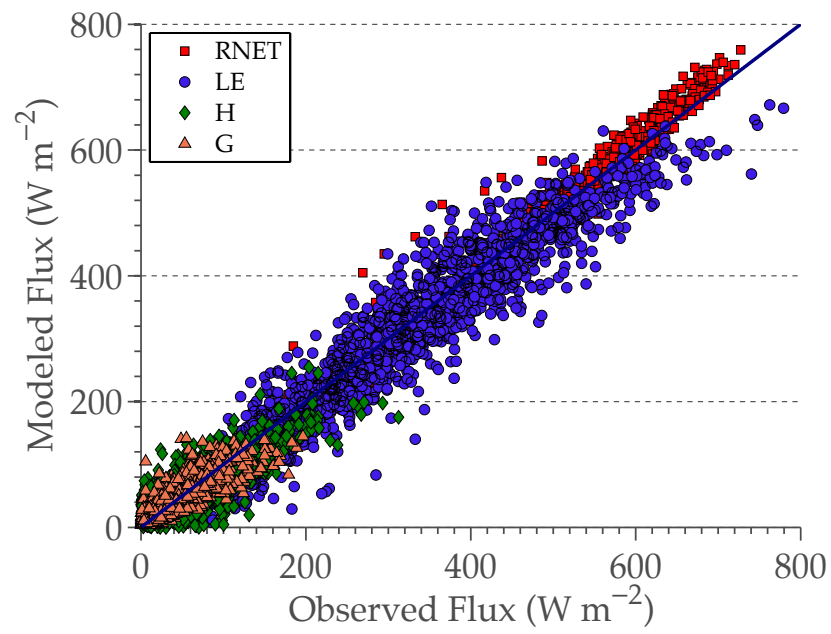

Figure 7. Comparison of hourly modeled and measured energy balance components for maize and soybean at Mead, NE, generated with TSEB-LUE using $\beta_{n}$ as a function of Chl.

While the impact of including the varying $\beta_{n}$ on total (canopy + soil) latent heat fluxes is not immediately evident given the conditions sampled in this study period, there was a significant impact on the partitioning between canopy and 


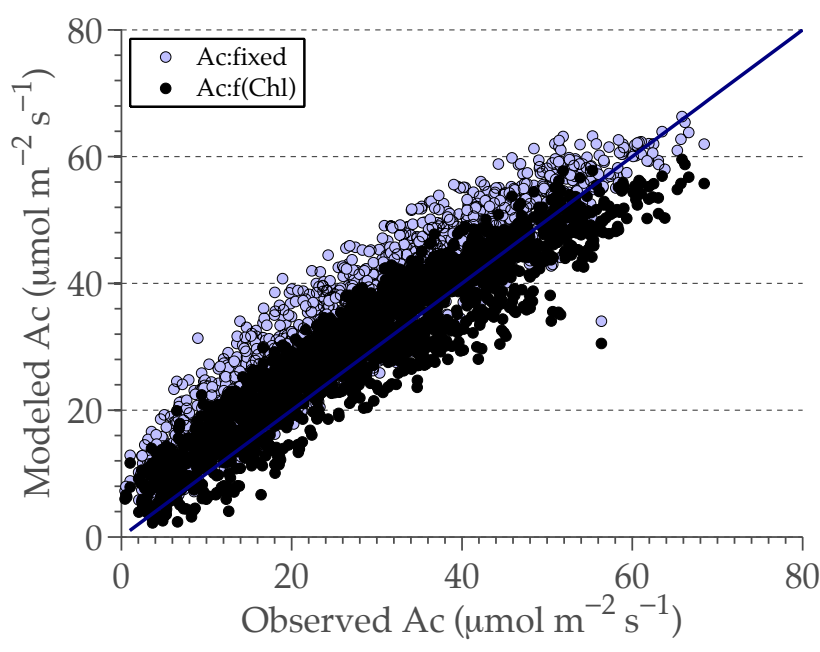

Figure 8. Comparison of hourly modeled and measured energy balance components for maize and soybean at Mead, NE, generated with TSEB-LUE using fixed values of $\beta_{n}$ (light-blue points) and $\beta_{n}$ as a function of Chl (black points).

soil latent heat (Fig. 6). In general, the predominant effect was to increase soil evaporation and decrease transpiration fluxes, indicating a shift of latent heat from the canopy to soil. Changes in the canopy latent heat fluxes are intimately (and positively) linked to changes in carbon assimilation through regulation via the canopy resistance (Anderson et al., 2008).

Scatterplot comparisons of modeled and measured hourly energy and carbon fluxes are shown in Figs. 7 and 8, respectively. Incorporation of time-varying $\beta_{n}$ serves to modulate the partition of the fluxes of carbon and water between the soil and canopy, but it has little impact on the total energy fluxes in this study (Table 3 ). In contrast, the overall impact on the canopy carbon flux is more pronounced, with a significant reduction in bias and increased goodness of fit (Fig. 8 and Table 3).

\subsection{Evaluation of daily-integrated fluxes}

Daytime-integrated fluxes of water, energy, and carbon were computed using the 5-day averaged hourly flux values integrated over daytime hours when the solar zenith angle is less than $80^{\circ}$. Figure 9 a shows the results of the daily fluxes forced by the fixed $\beta_{n}$. The latent heat fluxes are seen to be slightly overestimated at low- to mid-range values, whereas the sensible heat fluxes are slightly underestimated at mid- to high-range values. The results based on seasonally varying $\beta_{n}$ are quite similar (Fig. 9b), although the apparent overestimation of the latent heat fluxes seen in Fig. 9a has been slightly reduced. This improvement is reflected in the RMSD statistic, which changes from 1.44 to 1.41 (Table 4).

The use of a seasonally varying $\beta_{n}$ rather than a fixed $\beta_{n}$ markedly improves modeled carbon fluxes at the daily timescale (Fig. 10). Errors at daily time steps are signif-
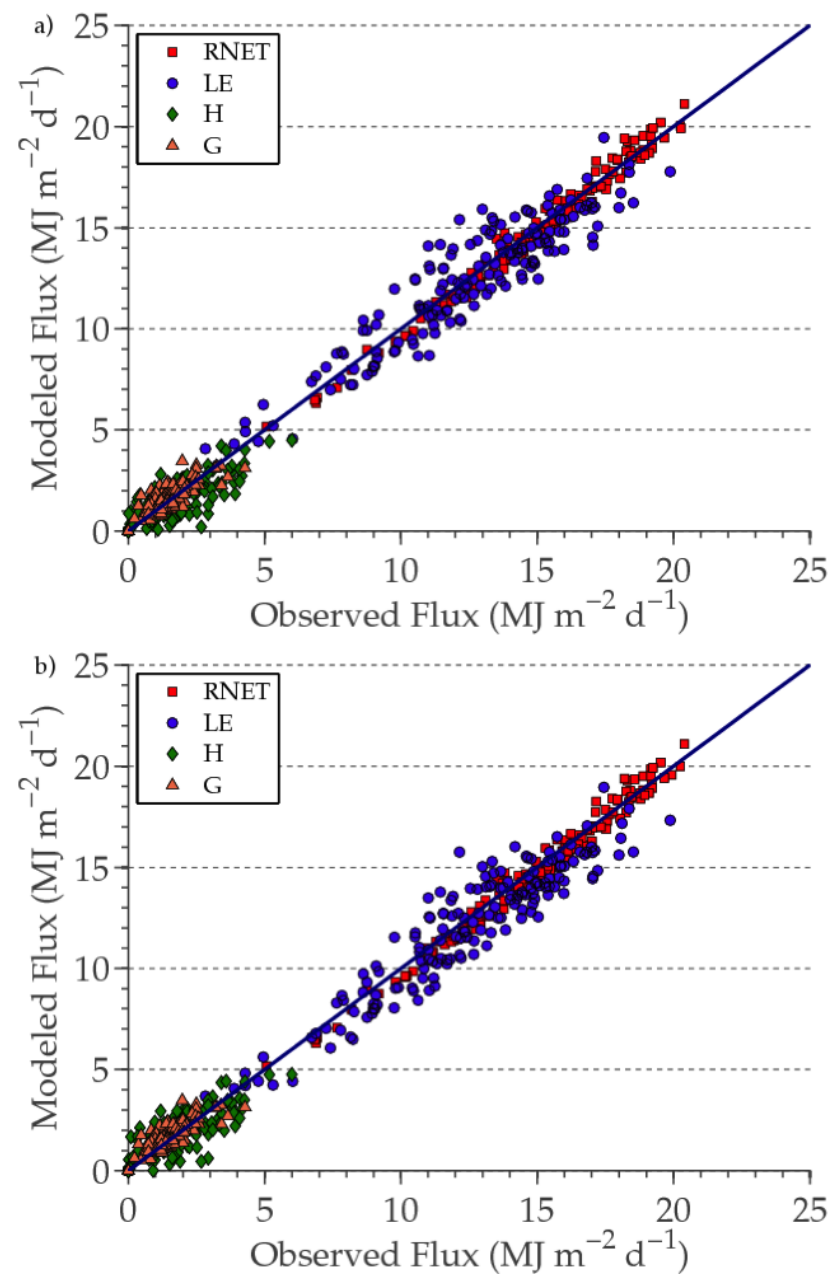

Figure 9. Comparison of daily modeled and measured energy balance components for maize and soybean at Mead, NE, using TSEBLUE with (a) fixed $\beta_{n}$ and (b) $\beta_{n}$ as a function of Chl.

icantly reduced over hourly model performance, with decreases in RMSD and MBE from 0.60 to 0.32 and 0.47 to $0.14 \mu \mathrm{mol} \mathrm{m}^{-2} \mathrm{~s}^{-1}$, respectively, and a decrease in relative error from 26 to $13 \%$ (Table 4).

\section{Summary and conclusions}

The results presented in this study indicate that leaf chlorophyll $(\mathrm{Chl})$ is closely related to the canopy nominal light use efficiency $\left(\beta_{n}\right)$ input required by TSEB-LUE for medium to dense vegetation. In addition, the relationship can be reasonably described with a single function for both soybean and maize, despite differences in photosynthetic pathway (C3 versus $\mathrm{C} 4$ ). The relationship between $\mathrm{Chl}$ and $\beta_{n}$ was found to be curvilinear with $\beta_{n}$ saturating for soybean around a value of 0.025 , corresponding to a Chl value of approximately $30\left(\mu \mathrm{g} \mathrm{cm}^{-2}\right)$, while maize appears to saturate at a $\beta_{n}$ value closer to 0.035 , corresponding to a $\mathrm{Chl}$ level of around 


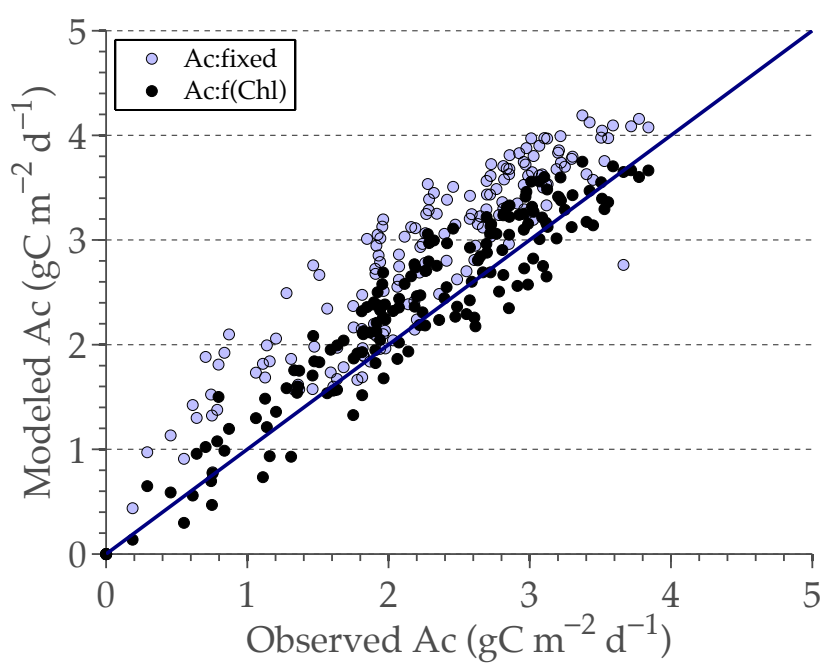

Figure 10. Comparison of hourly modeled and measured canopy carbon assimilation fluxes for maize and soybean at Mead, NE, generated with TSEB-LUE using fixed values of $\beta_{n}$ (light-blue points) and $\beta_{n}$ as a function of Chl (black points).

$60\left(\mu \mathrm{g} \mathrm{cm}^{-2}\right)$. These asymptotic values are in line with literature values and previous applications with the TSEB-LUE using fixed $\beta_{n}$.

During times of plant stress or senescence, the use of a fixed land-cover-specific nominal LUE representative of healthy vegetation is not appropriate. By allowing nominal LUE to respond to varying conditions of plant stress via Chl modulations, uncertainties in modeled fluxes of carbon are significantly reduced. While canopy carbon assimilation shows improved results especially in the senescing stage of the growing season, the impact is not apparent in total latent heat fluxes. However varying $\beta_{n}$ adjusts the partitioning of latent heat fluxes from the soil and canopy. Unfortunately information about the partitioning of the fluxes was not available for verification purposes.

The results indicate potential for improved monitoring of carbon fluxes using established relationships as a functional basis for using Chl as a proxy of plant condition and photosynthetic capacity. Because $\mathrm{Chl}$ can be estimated from remotely sensed data (Houborg and Anderson, 2009; Houborg et al., 2015), the approach outlined in this paper can be scaled up using satellite data with the potential for improved regional mapping of fluxes of carbon, water, and energy. For regional-scale mapping the challenge will be to establish the spatial distribution of species to inform the model for different nominal values (i.e., $\gamma_{n}$ ), which can vary between C3 and $\mathrm{C} 4$ plants. For agricultural areas the USDA's Cropland Data Layer (CDL) can be used; however, for other biomes a more robust species map may be needed than currently exists. By implementing the TSEB-LUE approach within the ALEXI/DisALEXI modeling system (Anderson et al., 2007), regional-scale modeling of not only water and energy but also carbon fluxes within a thermal-based modeling framework will become feasible.

Acknowledgements. The research presented here was funded by NASA Headquarters under the Terrestrial Ecology Program (grant NNH09ZDA001N). We appreciate the data provided by the Center for Advanced Land Management Information Technologies (CALMIT) and the Carbon Sequestration Program, University of Nebraska-Lincoln.

The U.S. Department of Agriculture (USDA) prohibits discrimination in all its programs and activities on the basis of race, color, national origin, age, disability, and, where applicable, sex, marital status, familial status, parental status, religion, sexual orientation, genetic information, political beliefs, reprisal, or because all or part of an individual's income is derived from any public assistance program. (Not all prohibited bases apply to all programs.) Persons with disabilities who require alternative means for communication of program information (Braille, large print, audiotape, etc.) should contact USDA's TARGET Center at (202) 720-2600 (voice and TDD). To file a complaint of discrimination, write to USDA, Director, Office of Civil Rights, 1400 Independence Avenue, S.W., Washington, D.C. 20250-9410, or call (800) 795-3272 (voice) or (202) 720-6382 (TDD). USDA is an equal opportunity provider and employer.

Edited by: G. Wohlfahrt

\section{References}

Alton, P. B., North, P. R., and Los, S. O.: The impact of diffuse sunlight on canopy light-use efficiency, gross photosynthetic product and net ecosystem exchange in three forest biomes, Glob. Change Biol., 13, 776-787, 2007.

Anderson, M. C., Norman, J. M., Meyers, T. P., and Diak, G. R.: An analytical model for estimating canopy transpiration and carbon assimilation fluxes based on canopy light-use efficiency, Agr. Forest Meteorol., 101, 265-289, 2000.

Anderson, M. C., Kustas, W. P., and Norman, J. M.: Upscaling Flux observations from local to continental scales using thermal remote sensing, Agron. J., 99, 240-254, 2007.

Anderson, M. C., Norman, J. M., Kustas, W. P., Houborg, R., Starks, P. J., and Agam, N.: A thermal-based remote sensing technique for routine mapping of land-surface carbon, water and energy fluxes from field to regional scales, Remote Sens. Environ., 112, 4227-4241, 2008.

Anderson, M. C., Kustas, W. P., Norman, J. M., Hain, C. R., Mecikalski, J. R., Schultz, L., González-Dugo, M. P., Cammalleri, C., d'Urso, G., Pimstein, A., and Gao, F.: Mapping daily evapotranspiration at field to continental scales using geostationary and polar orbiting satellite imagery, Hydrol. Earth Syst. Sci., 15, 223-239, doi:10.5194/hess-15-223-2011, 2011.

Baldocchi, D. D.: Assessing the eddy covariance technique for evaluating carbon dioxide exchange rates of ecosystems: past, present and future, Glob. Change Biol., 9, 479-492, 2003.

Ciganda, V. S., Gitelson, A. A., and Schepers, J.: Non-destructive determination of maize leaf and canopy chlorophyll content, J. Plant Physiol., 166, 157-167, 2009. 
DeLucia, E. H., Drake, J. E., Thomas, R. B., and Gonzalez-Meler, M.: Forest carbon use efficiency: is respiration a constant fraction of gross primary production?, Glob. Change Biol., 13, 11571167, 2007.

Evans, J. R.: Photosynthesis and nitrogen relationships in leaves of C3 plants, Oecologia, 78, 9-19, 1989.

Field, C. B.: Ecological scaling of carbon gain to stress and resource availability, in: Response of Plants to Multiple Stresses, edited by: Moony, H. A., Winner, W. E., and Pell, E. J., Academic Press, San Diego, 35-65, 1991.

Gitelson, A. A., Gritz, Y., and Merzlyak, M. N.: Relationships between leaf chlorophyll content and spectral reflectance and algorithms for non-destructive chlorophyll assessment in higher plant leaves, J. Plant Physiol., 160, 271-282, 2003a.

Gitelson, A. A., Viña, A., Arkebauer, T. J., Rundquist, D. C., Keydan, G., and Leavitt, B.: Remote estimation of leaf area index and green leaf biomass in maize canopies, Geophys. Res. Lett., 30, 1248, doi:10.1029/2002GL016450, 2003b.

Gitelson, A. A., Viña, A., Ciganda, V. S., Rundquist, D. C., and Arkebauer, T. J.: Remote estimation of canopy chlorophyll content in crops, Geophys. Res. Lett., 32, L08403, doi:10.1029/2002GL016450, 2005.

Gitelson, A. A., Viña, A., Verma, S. B., Rundquist, D. C., Arkebauer, T. J., Keydan, G. P., Leavitt, B., Leavitt, V., Burba, G. G., and Suyker, A. E.: Relationship between gross primary production and chlorophyll content in crops: implications for the synoptic monitoring of vegetation productivity, J. Geophys. Res., 111, D08S11, doi:10.1029/2005JD006017, 2006.

Gitelson, A. A., Peng, Y., Masek, J. G., Rundquist, D. C., Verma, S. B., Suyker, A., Baker, J. M., Hatfield, J. L., and Meyers, T.: Remote estimation of crop gross primary production with Landsat data, Remote Sens. Environ., 121, 404-414, 2012.

Goetz, S. J. and Prince, S. D.: Modelling terrestrial carbon exchange and storage: evidence and implications of functional convergence in light-use efficiency, in: Advances in Ecological Research, edited by: Fitter, A. H. and Raffaelli, D., Academic Press, San Diego, 28 57-92, 1999.

Goetz, S. J., Halthore, R. N., Hall, F. G., and Markham, B. L.: Surface temperature retrieval in a temperate grassland with multiresolution sensors, J. Geophys. Res., 100, 25397, doi:10.1029/94JD02684, 1995.

Gough, C. M.: Terrestrial primary production: fuel for life, Nature Education Knowledge, 3, 1-7, 2012.

Gower, S. T., Kucharik, C. J., and Norman, J. M.: Direct and indirect estimation of leaf area index, fAPAR, and net primary production of terrestrial ecosystems, Remote Sens. Environ., 70, 29-51, 1999.

Hatfield, J. L., Vauclin, M., Vieira, S. R., and Bernard, R.: Surface temperature variability patterns within irrigated fields, Agr. Water Manage., 8, 429-437, 1984.

Houborg, R. and Anderson, M. C.: Utility of an image-based canopy reflectance modeling tool for remote estimation of LAI and leaf chlorophyll content at regional scales, J. Appl. Remote Sens., 3, 033529, doi:10.1117/1.3141522, 2009.

Houborg, R., Anderson, M. C., and Daughtry, C. S. T.: Utility of an image-based canopy reflectance modeling tool for remote estimation of LAI and leaf chlorophyll content at the field scale, Remote Sens. Environ., 113, 259-274, 2009.
Houborg, R., Anderson, M. C., Daughtry, C. S. T., Kustas, W. P., and Rodell, M.: Using leaf chlorophyll to parameterize lightuse-efficiency within a thermal-based carbon, water and energy exchange model, Remote Sens. Environ., 115, 1694-1705, 2011.

Houborg, R., Cescatti, A., Migliavacca, M., and Kustas, W. P.: Satellite retrievals of leaf chlorophyll and photosynthetic capacity for improved modeling of GPP, Agr. Forest Meteorol., 177, 10-23, 2013.

Houborg, R., McCabe, M., Cescatti, A., Gao, F., Schull, M., and Gitelson, A.: Joint leaf chlorophyll content and leaf area index retrieval from Landsat data using a regularized model inversion system, in press, Remote Sens. Environ., doi:10.1016/j.rse.2014.12.008, online first, 2015.

Kergoat, L., Lafont, S., Arneth, A., Le Dantec, V., and Saugier, B.: Nitrogen controls plant canopy light-use efficiency in temperate and boreal ecosystems, J. Geophys. Res., 113, 4017, doi:10.1029/2007JG000676, 2008.

Kosugi, Y., Shibata, S., and Kobashi, S.: Parameterization of the $\mathrm{CO}_{2}$ and $\mathrm{H}_{2} \mathrm{O}$ gas exchange of several temperate deciduous broad-leaved trees at the leaf scale considering seasonal changes, Plant Cell Environ., 26, 285-301, 2003.

Kustas, W. P. and Norman, J. M.: Evaluation of soil and vegetation heat flux predictions using a simple two-source model with radiometric temperatures for partial canopy cover, Agr. Forest Meteorol., 94, 13-29, 1999.

Kustas, W. P. and Norman, J. M.: A two-source energy balance approach using directional radiometric temperature observations for sparse canopy covered surfaces, Agron. J., 92, 847-854, 2000 .

Kustas, W. P., Norman, J. M., Schmugge, T. J., and Anderson, M. C.: Mapping surface energy fluxes with radiometric temperature, in: Thermal Remote Sensing in Land Surface Processes, edited by: Quattrochi, D. A. and Luvall, J. C., CRC Press, Boca Raton, 205-254, 2004.

Medlyn, B. E.: Physiological basis of the light use efficiency model, Tree Physiol., 18, 167-176, 1998.

Moncrieff, J. B., Malhi, Y., and Leuning, R.: The propagation of errors in long-term measurements of land-atmosphere fluxes of carbon and water, Glob. Change Biol., 2, 231-240, doi:10.1111/j.1365-2486.1996.tb00075.x, 1996.

Monteith, J. L.: Solar radition and productivity in tropical ecosystems, J. Appl. Ecol., 9, 747-766, 1972.

Monteith, J. L.: Climate and the efficiency of crop production in Britain, Philos. T. R. Soc. Lon. B, 281, 277-294, 1977.

Norman, J. M. and Arkebauer, T. J.: Predicting canopy photosynthesis and light-use efficiency from leaf characteristics, in: Modeling Crop Photosynthesis - from Biochemistry to Canopy, edited by: Boote, K. J. and Loomis, R. S., Crop Science Society of America and American Society of Agronomy, 75-94, 1991.

Norman, J. M., Garcia, R., and Verma, S. B.: Soil surface $\mathrm{CO}_{2}$ fluxes and the carbon budget of a grassland, J. Geophys. Res., 97, 18845-18853, doi:10.1029/92JD01348, 1992.

Norman, J. M., Kustas, W. P., and Humes, K. S.: Source approach for estimating soil and vegetation energy fluxes in observations of directional radiometric surface-temperature, Agr. Forest Meteorol., 77, 263-293, 1995.

Peng, Y. and Gitelson, A. A.: Remote estimation of gross primary productivity in soybean and maize based on total crop chlorophyll content, Remote Sens. Environ., 117, 440-448, 2012. 
Peng, Y., Gitelson, A. A., Keydan, G., Rundquist, D. C., and Moses, W.: Remote estimation of gross primary production in maize and support for a new paradigm based on total crop chlorophyll content, Remote Sens. Environ., 115, 978-989, 2011.

Prince, S. D.: A model of regional primary production for use with coarse resolution satellite data, Int. J. Remote Sens., 12, 13131330, 1991.

Ruimy, A., Kergoat, L., Bondeau, A., and Intercomparison, ThE. P. OF. ThE. P. NpP. M.: Comparing global models of terrestrial net primary productivity (NPP): analysis of differences in light absorption and light-use efficiency, Glob. Change Biol., 5, 56-64, doi:10.1046/j.1365-2486.1999.00007.x, 1999.

Sage, R. F. and Pearcy, R. W.: The Nitrogen Use Efficiency of C3 and C4 Plants, Plant Physiol., 84, 959-963, doi:10.1104/pp.84.3.954, 1987.

Santanello, J. A. and Friedl, M. A.: Diurnal covariation in soil heat flux and net radiation, J. Appl. Meteorol., 42, 851-862, 2003.

Schlemmer, M., Gitelson, A. A., Schepers, J., Ferguson, R., Peng, Y., Shanahan, J., and Rundquist, D.: Remote estimation of nitrogen and chlorophyll contents in maize at leaf and canopy levels, Int. J. Appl. Earth Obs., 25, 47-54, 2013.

Suyker, A. E. and Verma, S. B.: Coupling of carbon dioxide and water vapor exchanges of irrigated and rainfed maize-soybean cropping systems and water productivity, Agr. Forest Meteorol., 150, 553-563, 2010.

Suyker, A. E. and Verma, S. B.: Gross primary production and ecosystem respiration of irrigated and rainfed maize-soybean cropping systems over 8 years, Agr. Forest Meteorol., 165, 12 24, 2012.

Theobald, J. C., Mitchell, R. A. C., Parry, M. A. J., and Lawlor, D. W.: Estimating the Excess Investment in Ribulose-1, 5-Bisphosphate Carboxylase/Oxygenase in Leaves of Spring Wheat Grown under Elevated $\mathrm{CO}_{2}$, Plant Physiol., 21, 945-955, doi:10.1104/pp.118.3.945, 1998.
Twine, T. E., Kustas, W. P., Norman, J. M., Cook, D. R., Houser, P. R., Meyers, T. P., Prueger, J. H., Starks, P. J., and Wesely, M. L.: Correcting eddy-covariance flux underestimates over a grassland, Agr. Forest Meteorol., 103, 279-300, 2000.

Ustin, S. L., Smith, M. O., Jacquemoud, S., Verstraete, M., and Govaerts, Y.: Geobotany: vegetation mapping for earth sciences, in: Manual of Remote Sensing, Remote Sensing for the Earth Sciences, Vol. 3, edited by: Rencz, A. and Ryerson, R., John Wiley and Sons, USA, 1999.

Viña, A.: Remote estimation of leaf area index and biomass in corn and soybean, Gitelson, A. A., ProQuest Dissertations and Theses, Ph.D. thesis, The University of Nebraska, Lincoln, 2004.

Viña, A., Gitelson, A. A., Nguy-Robertson, A. L., and Peng, Y.: Comparison of different vegetation indices for the remote assessment of green leaf area index of crops, Remote Sens. Environ., 115, 3468-3478, 2011.

Wilson, K. B., Baldocchi, D. D., and Hanson, P. J.: Leaf age affects the seasonal pattern of photosynthetic capacityand net ecosystem exchange of carbon in a deciduous forest, Plant Cell Environ., 24, 571-583, 2001.

$\mathrm{Xu}, \mathrm{L}$. and Baldocchi, D. D.: Seasonal trends in photosynthetic parameters and stomatal conductance of blue oak (Quercus douglasii) under prolonged summer drought and high temperature, Tree Physiol., 23, 865-877, 2003.

Zarco-Tejada, P. J., Miller, J. R., Mohammed, G. H., Noland, T. L., and Sampson, P. H.: Vegetation stress detection through chlorophyll $a+b$ estimation and fluorescence effects on hyperspectral imagery, York Univ, Ctr Res Earth and Space Sci, Toronto, ON M3J 1PE, Canada, J. Environ. Qual., 31, 1433-1441, 2002. 